\title{
A próxima pandemia: estamos preparados?
}

\section{The next pandemic: Are we ready?}

\author{
Haroldo José de Matos ${ }^{1,2}$ \\ ' Editor Científico da Rev Pan-Amaz Saúde, Instituto Evandro Chagas/SVS/MS, Ananindeua, Pará, Brasil \\ 2 Instituto Evandro Chagas/SVS/MS, Serviço de Epidemiologia, Setor de Atendimento Médico Unificado, Ananindeua, Pará, Brasil
}

\section{UM OLHAR SOBRE A PANDEMIA DE 1918, 100 ANOS APÓS}

Neste ano, 2018, completamos 100 anos da maior pandemia de influenza já registrada na história, a famosa Gripe Espanhola de 1918'. Embora conhecida como "espanhola", não teve sua origem na Espanha. A primeira onda da epidemia na verdade foi detectada em Kansas, nos Estados Unidos. Nessa pandemia, chamada de "mãe de todas as pandemias" há diferentes estimativas de óbitos pela infecção, que variam entre 20 até 50 milhões de óbitos em todo o mundo. A causa dessa pandemia foi o vírus Influenza A (H1N1). Recentemente, esse vírus foi isolado e sequenciado, fazendo-o reviver ${ }^{3}$. Há ainda um grande debate sobre as possíveis causas associadas à magnitude da letalidade desse vírus. As possíveis explicações variam desde uma virulência especial desse $\mathrm{H} 1 \mathrm{Nl}$, o que não se observou na cepa circulante na pandemia de 2009, até fatores do sistema imune dos hospedeiros, certamente suscetíveis.

\section{A ORIGEM DA DIVERSIDADE}

Há dois tipos de mudança no material genético do Influenza que são fonte de diversidade do vírus, e que desafiam o sistema imune animal. Eles são apelidados de drift e shift antigênicos ${ }^{4}$. Os drift antigênicos são pequenas derivações nos genes do Influenza que produzem vírus que são na prática muito semelhantes aos vírus que os deram origem, o que os coloca em uma posição muito próxima na árvore filogenética. Essas propriedades antigênicas proximamente compartilhadas fazem com que o sistema imune os possa reconhecer e responder a esse desafio antigênico de um modo mais ou menos eficaz.

Porém, essas pequenas derivações genéticas podem se acumular ao longo do tempo e resultar em vírus que são antigenicamente diferentes o suficiente para que o sistema imune não mais os reconheça de modo eficaz. Essa diversidade explica por que se pode adquirir repetidos episódios de infecção pelo vírus Influenza e por que a composição da vacina precisa ser atualizada anualmente.

Já o shift antigênico traz um desafio bem mais complexo. Representa uma mudança mais expressiva na estrutura do material genético, e ocorre de uma forma abrupta nos vírus Influenza $A$, dando origem a um novo subtipo do vírus. Essas mudanças maiores resultam em proteínas novas não reconhecidas pelos sistemas imunes dos animais infectados anteriormente por outros tipos de vírus Influenza. São realmente novas proteínas hemaglutininas e neuraminidases na cápsula proteica do vírus, dando origem a novas combinações dessas proteínas (ex.: H3N2; H7N9, H1N1, etc.). Esse shift ocorreu em 1918, resultando na maior pandemia de Influenza conhecida, a Gripe Espanhola, e voltou a ocorrer em 2009, em uma nova pandemia que também rapidamente se disseminou pelos cinco continentes, mas felizmente sem os desfechos trágicos de 100 anos atrás.

Enquanto o processo de drift antigênico ocorre comumente nos tipos $A$ e B, o shift antigênico ocorre somente nos vírus tipo $\mathrm{A}$.

\section{OS CICLOS PANDÊMICOS}

Infecções pandêmicas são, de fato, marca registrada do vírus Influenza tipo A, e essas marcas estão registradas ao longo da história humana. Consta que a conquista da Europa por Carlos Magno teria sido retardada por uma epidemia de influenza que se propagou por toda a Europa e dizimou uma parte de seu exército. Um registro digno de confiança, contudo, foi o da pandemia de 1850, que se disseminou por meio de rotas comerciais atingindo a Europa, as Américas e a África. Há dados que mostram que algumas colônias espanholas na América ficaram quase despovoadas'. Foram feitos registros ainda de pandemias que ocorreram desde o século XVIII, em 1729, 1732, $1781,1830,1833$ e 1889, até chegarmos à grande pandemia de 1918-1919. Então, parece existir certo padrão temporal, fazendo com que a cada geração (em torno de 80 anos) os ciclos se repitam incluindo um shift desafiador.

Os registros da pandemia de 1918 mostram que a epidemia se disseminou em todo o mundo em menos de cinco meses. Alguns aspectos dessa pandemia realmente são impressionantes. Há estimativas de pelo menos 21 milhões de óbitos. Algumas estimativas chegam até a 50 milhões. Um fato que chama atenção é a ocorrência predominante de óbitos entre os adultos jovens e crianças. Houve ainda notícias de pessoas que embarcaram no metrô de Nova York, em Coney Island, apenas com sintomas inespecíficos, como cansaço, e foram encontradas mortas na estação de Columbus Circle, 45 minutos depois'. Há ainda relatos de que povoados inteiros de esquimós desapareceram completamente em regiões longínquas do Alasca'. Dados dos patologistas britânicos apontavam a hemorragia pulmonar como a principal causa de óbito, o que não se havia ainda observado nas epidemias ocorridas em 1873 
e 1889. Mas a epidemia não se restringiu ao hemisfério norte. Há dados impressionantes de que um de cada 20 habitantes de Gana, na África Ocidental, morreu da infecção pelo vírus Influenza entre $1^{\circ}$ de setembro e $1^{\circ}$ de novembro de 19185. Na Oceania, a população de Samoa Ocidental foi de tal modo impactada pela epidemia que quase todos os 38.000 habitantes do país foram infectados e 7.500 morreram (20\% da população), uma estimativa acima da média da letalidade da epidemia ${ }^{6}$. Alguma reflexão ainda é necessária para se estabelecer bem os fatores associados à alta letalidade dessa epidemia. É preciso lembrar que, em 1918, estava terminando uma guerra extensa e duradoura, conhecida como a I Guerra Mundial, e havia fatores limitantes de nutrição e fatores socioeconômicos ligados ao empobrecimento e condições de vida das populações. Não se pode esquecer ainda o fato de que a maioria dos casos fatais estava associada a infecções secundárias por bactérias, e que, nessa época, não estavam ainda disponíveis antibióticos, a não ser derivados arsenicais usados no tratamento da sífilis ${ }^{6}$.

\section{AS PESQUISAS}

A Gripe Espanhola, no entanto, gerou uma intensa pesquisa na área básica. Em 1932, Richard Shope fez uma experiência crucial sobre a origem do vírus Influenza A, que causou a pandemia de 1918-1919. Ele removeu secreções nasais de porcos domésticos infectados pelo vírus Influenza e os esfregou nas bocas de outros animais, conseguindo infectá-los. Daí a gripe associada ao vírus Influenza H1N1 ser conhecido como gripe suína. Em 1933, o vírus foi finalmente isolado e, em 1935, Shope demonstrou que indivíduos que haviam passado pela epidemia de 1918-1919 possuíam anticorpos contra o vírus da gripe suína, mas não indivíduos que nasceram depois de 1920. Kilbourne ${ }^{4}$, em 1973, demonstrou que um fator associado à virulência dos vírus Influenza era a densidade da proteína neuraminidase na superfície da estrutura viral. Quanto maior a densidade dessa proteína na superfície do vírus maior a facilidade de sua capacidade de infectar novas células do organismo. Essa tese pode ser comprovada na pandemia de 1957 (H2N2), com letalidade elevada. Em 1968, houve ainda uma grande pandemia (H3N2), embora menos fatal que a de 1957, mas com maior extensão. Em 1976, também houve evidência da circulação do vírus H1N1 nos EUA, o que ocasionou uma intensa pesquisa por uma vacina eficaz. E, em 2009, enquanto todos os olhares estavam voltados para a gripe aviária $\mathrm{H} 5 \mathrm{~N} 1$, eis que ressurge o vírus $\mathrm{H1N1}$, que se espalhou rapidamente pelo globo. No entanto, felizmente, a letalidade não foi como a da Gripe Espanhola, e rapidamente uma vacina eficaz tornou-se disponível. Hoje há evidências de que os vírus Influenza têm origem nas aves e modificam-se depois nos porcos, onde ocorrem as mutações que vão infectar a espécie humana. Mas o ápice da pesquisa relacionada à epidemia de influenza de 1918 ocorreu quando, a partir de 1995, iniciou-se a pesquisa para o sequenciamento do vírus da epidemia de 1918-1919 e, no início do século XXI, em 2005, quando foi apresentado ao mundo o sequenciamento do vírus H1N1 a partir de material congelado de esquimós e outras amostras ${ }^{3}$. Essas pesquisas apontam para o fato de que as cepas dos vírus Influenza circulantes no mundo desde então derivam, em grande parte, do RNA do vírus H1N1 da pandemia de 1918-1919.

\section{PERSPECTIVA}

\section{ESTAMOS PREPARADOS PARA A PRÓXIMA PANDEMIA?}

Uma questão chave para se responder a essa pergunta é voltarmos à questão da previsibilidade de uma nova pandemia. Embora algum padrão cíclico possa ser identificado nas pandemias de influenza, como discutido acima, há um consenso hoje de que a melhor aproximação é uma probabilidade. De fato, alguns epidemiologistas defendem a ideia de que a previsão de uma nova pandemia se assemelha ao processo da previsão do tempo, "governada" por sistemas caóticos ${ }^{8}$.

Nesse sentido, a preparação para as situações de emergência, como as pandemias, passam por três etapas essenciais, aprimorando os instrumentos de que dispomos no dia a dia.

\section{1) Aprimoramento da vigilância epidemiológica}

Essa é uma etapa fundamental da preparação para uma eventual pandemia. Um passo importante nesse aprimoramento foi a entrada em vigor do Novo Regulamento Sanitário Internacional (2005). Nesse sentido, esse regulamento aponta para um modelo de vigilância epidemiológica que interconecta rapidamente todos os países ligados à Organização Mundial da Saúde e também cria padrões de funcionamento para as vigilâncias locais. No Brasil, essa discussão deu origem aos Centros de Informações Estratégicas em Vigilância em Saúde e a uma nova reformulação da vigilância epidemiológica, que incluiu a criação da Secretaria de Vigilância em Saúde, a qual hoje está ligado o Instituto Evandro Chagas. $\bigcirc$ aprimoramento da vigilância inclui certamente a incorporação de novas tecnologias de informação e comunicação?. Um aspecto fundamental é a forte presença de uma base laboratorial de pesquisa e apoio à vigilância epidemiológica, com a participação de institutos de pesquisa e laboratórios centrais de apoio à vigilância. Um exemplo disso é a vigilância sentinela de influenza, da qual o próprio Instituto Evandro Chagas também participa como unidade sentinela. Outro aspecto tão ou mais importante que a rede laboratorial é a capacitação de recursos humanos, que inclui o EpiSUS, curso de capacitação para epidemiologistas de campo, do Ministério da Saúde.

2) Pesquisa clínica

A formação de redes de pesquisa clínica voltadas para a produção de evidências da eficácia de vacinas e novos medicamentos contra as potenciais fontes de pandemia, incluindo agentes emergentes e reemergentes, é também 
fundamental. Essas redes de pesquisa clínica incluem ainda a formação de novos pesquisadores clínicos, em especial nas Regiões Norte e Nordeste do Brasil.

3) Estrutura laboratorial voltada à formação de novos insumos e biológicos

Finalmente, uma preparação para o enfrentamento de novas pandemias, como as de influenza, inclui o fortalecimento na capacidade de produção de novos insumos e biológicos, como vacinas e fármacos, com capacidade de previsão de aumento de produção e distribuição rápidas frente a situações de emergência.

Ao olharmos novamente para a pandemia de influenza de 1918, não podemos deixar de trazer um olhar tristemente nostálgico, de um mundo saindo de uma guerra que mudou a geografia e a face do mundo atual, e relembramos o soneto de John McCrae...
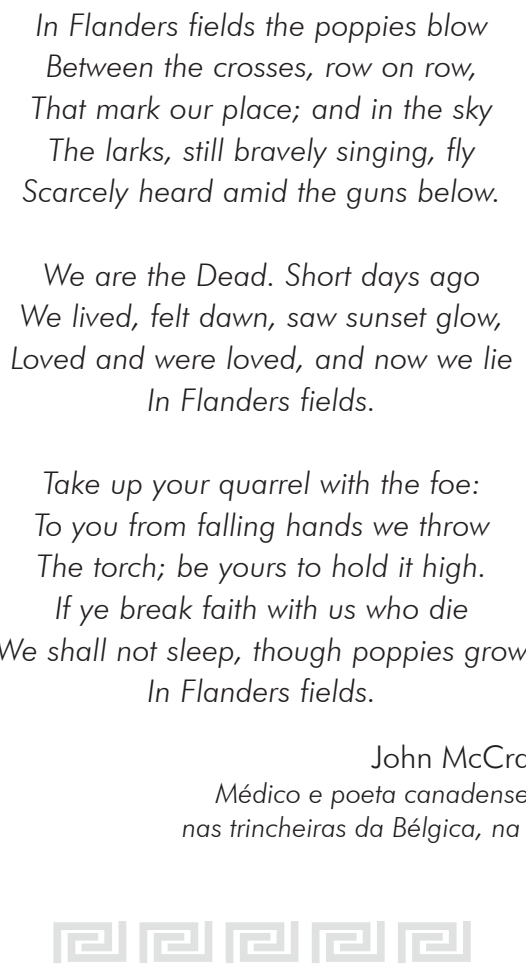

\section{REFERÊNCIAS}

1 Beveridge WIB. The chronicle of influenza epidemics. Hist Philos Life Sci 1991;13(2):223-34.

2 Taubenberger JK, Morens DM. 1918 influenza: the mother of all pandemics. Emerg Infect Dis. 2006 Jan; 12(1):15-22.

3 Taubenberger JK, Reid AH, Lourens RM, Wang R, Jin G, Fanning TG. Characterization of the 1918 influenza virus polymerase genes. Nature. 2005 Oct;437(7060):889-93.

4 Kilbourne ED. An explanation of the interpandemic antigenic mutability of influenza viruses. J Infect Dis. 1973 Nov; 128(5):668-70.

5 Scott D. Epidemic disease in Ghana 1901-1960. London: Oxford University Press; 1965.

6 Garrett L. The coming plague: newly emerging diseases in a world out of balance. New York: Farrar, Straus and Giroux; cl994.

7 Beare AS, Craig JW. Virulence for man of a human influenza-A virus antigenically similar to "classical" swine viruses. Lancet. $1976 \mathrm{Jul} ; 2(7975): 4-5$.

8 Furtado BA, Sakowski PAM, Tóvolli MH, editores. Modelagem de sistemas complexos para políticas públicas. Brasília: IPEA; 2015.

9 Gates B. Innovation for pandemics. N Engl J Med. 2018 May;378(22):2057-60. 